\title{
PEMBELAJARAN APLIKATIF PONDOK PESANTREN DAN DAMPAKNYA TERHADAP KUALITAS OUTCOME SISWA \\ (STUDI KASUS DI PONDOK PESANTREN DARUNNAJAH, JAKARTA)
}

\author{
Nurbaiti \\ Universitas Islam Negeri Syarif Hidayatullah Jakarta \\ nurbaiti.uin@gmail.com
}

\section{Abstract}

Education is the process of humanizing human beings, in other words, education is a humanization process, thus the learning process must be adapted to the human condition. However, there are differences in interpret humanizing human beings, so, resulting the differences in opinion between humanist education according to Islam with humanist education according to western theory.

Islam sees humanizing human beings by giving freedom to humans as long as it is not contrary to Islam, thus human freedom is not unlimited freedom. This is contrast to the western-based view of humanist education which states that humanist education is education by giving freedom to the students during the learning process. The implication of humanist learning according to Islam which came to be known as humanistic Islamic Education. It is the applicative learning of Islamic Boarding School. Learning with this model, student practice directly about the material that they have learnt. Thus, education is a habit. This means that to improve the quality of outcome needs to be given the education through habituation. The higher level of habituation performed, the higher quality of outcome. 
The outcomes quality in Islamic Boarding School Darunnajah is quite good. It can be seen that the alumni of Islamic Boarding School Darunnajah are accepted in Gajah Mada University (UGM), Institut Teknologi Bandung (ITB), Institut Pertanian Bogor (IPB) and Institut Agama Islam Negeri (IAIN) Sunan Ampel. Even many of them are continuing their education abroad, such as : Malaysia, Cairo (Egypt), Madinah and England, while with Pakistan, the cooperation is just opened in 2017.

Keywords: Islamic boarding school, Islamic humanistic education, Applicative learning, Outcome.

\section{Abstrak}

Pendidikan merupakan proses memanusiakan manusia, dengan kata lain pendidikan merupakan proses humanisasi, dengan demikian proses pembelajaran harus disesuaikan dengan keadaan manusia. Namun terdapat perbedaan dalam memaknai memanusiakan manusia, sehingga timbul perbedaan pendapat antara pendidikan humanis menurut agama Islam dengan pendidikan humanis menurut teori Barat.

Islam memandang memanusiakan manusia adalah dengan memberikan kebebasan kepada manusia selama tidak bertentangan dengan agama Islam, dengan demikian kebebasan manusia bukanlah kebebasan tanpa batas. Hal ini berbeda dengan pandangan pendidikan humanis versi barat yang menyatakan bahwa pendidikan humanis adalah pendidikan dengan memberikan kebebasan pada siswa selama proses pembelajaran.

Implikasi dari pembelajaran humanis menurut Islam yang kemudian dikenal dengan nama Pendidikan Humanistik Islami adalah pembelajaan aplikatif pondok pesantren. Pembelajaran dengan model ini, santri/siswa mempraktekkan langsung tentang materi yang sudah dipelajarinya. Dengan demikian, pendidikan merupakan pembiasaan. Hal ini berarti untuk meningkatkan kualitas outcome maka perlu diberikan pendidikan melalui 
pembiasaan. Semakin tinggi tingkat pembiasaan yang dilakukan maka semakin tinggi pula kualitas outcome.

Kualitas outcome pondok pesantren Darunnajah cukup baik, hal ini bisa dilihat bahwa alumni pondok pesantren Darunnajah diterima di Universitas Gajah Mada (UGM), Institut Teknologi Bandung (ITB), Institut Pertanian Bogor (IPB) dan Institut Agama Islam Negeri (IAIN) Sunan Ampel atas beasiswa dari Departemen Agama. Bahkan banyak diantara mereka yang melanjutkan pendidikan ke luar negeri, yaitu : Malaysia, Kairo (Mesir), Madinah dan Inggris, sedangkan dengan Pakistan baru pada tahun 2017 ini dibuka kerjasama.

Kata Kunci: Pondok Pesantren, Pendidikan Humanistik Islam, Pembelajaran Aplikatif, Outcome. 


\section{A. PENDAHULUAN}

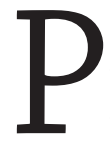
endidikan merupakan usaha yang dilakukan agar terjadi perubahan kearah perbaikan, al-Hazami menyatakan, pendidikan bukan hanya proses mentransfer ilmu, tetapi lebih kepada proses perubahan kearah perbaikan (ișlāh), ${ }^{1}$ sehingga pendidikan diartikan sebagai setiap usaha yang ditujukan untuk mendidik dan membangun kepribadian manusia pada semua aspek, baik aspek spiritual, emosional, moral dan lain sebagainya. ${ }^{2}$

Produk dari pendidikan adalah output dan outcome. Output merupakan hasil langsung setelah proses pembelajaran, sedangkan outcome adalah hasil pendidikan setelah output. UNICEF mendefinisikan outcome sebagai hasilyang mencakup pengetahuan, keterampilan, sikap dan terkait dengan tujuan nasional. ${ }^{3}$

Dengan demikian, kualitas outcome pendidikan merupakan hasil dari proses pembelajaran dalam bentuk jangka panjang, baik berupa kemampuan santri melanjutkan ke jenjang pendidikan selanjutnya maupun kemampuan santri mendapatkan pekerjaan di lingkungan masyarakat.

Kualitas outcome perlu ditingkatkan, tidak hanya dalam kemampuan pengetahuan saja tetapi juga dalam bentuk keterampilan dan sikap santri, sehingga diperlukan bentuk pendidikan yang dapat menjadikan santri tumbuh menjadi insan yang seluruh potensinya dapat tumbuh dan berkembang secara maksimal dan proporsional.

Tujuan pendidikan Islam menurut Rayan adalah membangun manusia menuju pencapaian nilai-nilai kemanusiaan. Pendidikan Islam juga bertujuan adanya keseimbangan antara akal, pikiran dan etika, ${ }^{4}$ sehingga tujuan pendidikan Islam adalah adanya keseimbangan antara kecerdasan akal, pikiran dan etika.

1 Khalid Bin Hamid al-Hazami.Ușūl al-Tarbiyah al-Islāmīyah (al-Madīnah al-Munawwarah: Dār 'Alam al-Kutub, 2000), h. 17

2 Ibrahim Mohammad Hamm, "Islamic Perspective of Education and Teachers", European Journal of Social Science 30, 2 (2012), h. 224.

3 UNICEF. “Defining Quality in Education.”United Nations Children's Fund (June, 2000), h. 3.

4 Sobhi Rayan. "Islamic Philosophy of Education." International Journal of Humanities and Social Science 2,19 (Special Issue, October, 2012), h. 155/ 150 -156 
Proses pendidikan Islam dapat diaplikasikan melalui proses pembelajaran Islami yang bertujuan agar setiap individu memiliki tanggung jawab yang besar untuk dapat mengembangkan dirinya serta mengaktualisasikan dirinya sebagai manusia dan sebagai makhluk Tuhan yang mempunyai kewajiban beribadah kepada Allah. ${ }^{5}$

Hakekat pendidikan merupakan proses humanisasi. Hal ini berimplikasi pada proses kependidikan dengan orientasi pengembangan aspek-aspek memanusiakan manusia baik aspek fisik-biologis maupun aspek rohaniah-psikologis. Pendidikan dengan memperhatikan aspek hakiki manusia dikenal dengan pendidikan humanis, yang bertujuan memanusiakan manusia, sehingga melalui pendidikan seluruh potensi baik dalam diri santri dapat tumbuh secara penuh dan menjadi pribadi utuh yang bersedia memperbaiki kehidupan.

Pendidikan humanistik Islami merupakan pengintegrasian antara pendidikan humanis dengan pendidikan Islam, yaitu pendidikan humanistik yang menekankan kemerdekaan individu diintegrasikan dengan pendidikan Islam, dengan tujuan agar dapat membangun kehidupan sosial yang menjamin kemerdekaan dengan tidak meninggalkan ajaran Islam. Kemerdekaan dalam pendidikan humanistik Islami menurut Musthofa dibatasi oleh nilai-nilai agama Islam. ${ }^{6}$

Proses pembelajaran Islami bertujuan agar setiap individu memiliki tanggung jawab yang besar untuk dapat mengembangkan dirinya serta mengaktualisasikan dirinya sebagai manusia, makhluk Tuhan yang paling mulia diantara sesama makhluk, sekaligus mampu memerankan dirinya dengan baik sebagaimana yang telah diharapkan sesuai dengan perintah Tuhan sebagai penciptanya.

Seperti dikemukakan oleh Firdaus dan Jani, pendidikan dalam agama Islam tidak hanya untuk memperoleh pengetahuan

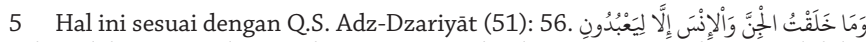
"Dan aku tidak menciptakan jin dan manusia melainkan supaya mereka mengabdi kepada-Ku".

6 Musthofa. "Pendidikan Humanis dalam Islam."dalam Jurnal Kajian Islam 3,2 (Agustus, 2011), h. 166. 
intelektual saja, tetapi lebih kepada pembentukan karakter individu, sehingga manusia dapat berperilaku sebagai khaliffatullāh fi al-ard (khalifah Allah di bumi). ${ }^{7} \mathrm{Hal}$ ini berarti bahwa pendidikan humanistik Islami merupakan pendidikan humanis yang bertujuan untuk membentuk peserta didik selain memperoleh pengetahuan secara intelektual, tetapi juga membentuk karakter peserta didik menjadi berperilaku sebagai khalifah Allah di bumi, oleh karena itu proses pembelajaran yang diberikan harus sejalan dengan ajaran Islam.

Salah satu metode pembelajaran dalam pendidikan humanistik Islami adalah metode pembiasaan. ${ }^{8}$ Pembiasaan merupakan upaya praktis dalam pendidikan dan pembinaan anak. Hasil dari pembiasaan yang dilakukan seorang pendidik adalah terciptanya suatu kebiasaan bagi anak didiknya. Seorang anak yang terbiasa mengamalkan nilai-nilai ajaran Islam lebih dapat diharapkan dalam kehidupannya nanti menjadi seorang Muslim yang saleh.

Dalam kehidupan sehari-hari pembiasaan itu sangat penting, karena pembiasaan akan memberikan kesempatan kepada peserta didik agar terbiasa mengamalkan ajaran agamanya, baik secara individual maupun secara berkelompok dalam kehidupan seharihari. Berawal dari pembiasaan, peserta didik membiasakan dirinya melakukan sesuatu yang lebih baik.

Penanaman pembiasaan yang baik, sangat penting dilakukan sejak awal kehidupan anak. Agama Islam sangat mementingkan pendidikan pembiasaan, dengan pembiasaan itulah diharapkan peserta didik mengamalkan ajaran agamanya secara berkelanjutan. Pendidikan melalui pembiasaan dapat dilakukan dalam pendidikan humanistik Islami, yaitu pendidikan yang memperhatikan aspek manusia, baik sebagai individu maupun sebagai bagian dari masyarakat.

7 Raudatul Firdaus Binti Fatah Yasin and Mohammad Shah Jani. "Islamic Education: The Phylosophy, Aim, and Main Feature," dalam International Journal of Education and Research1,10 (Oktober, 2010), h. 14.

8 Metode pembiasaan adalah sebuah cara yang dapat dilakukan untuk membiasakan anak didik berfikir, bersikap dan bertindak sesuai dengan tuntunan agama Islam. Contohnya ayat pengharaman khomar. 
Pembiasaan dalam pendidikan humanis menurut Islam merupakan membiasakan santri melalui pendidikan humanis yang dilandasi pada agama Islam. Pendidikan humanis dalam perspektif Islam mempunyai pandangan, pada dasarnya manusia memiliki dua aspek dalam kehidupannya, yaitu aspek baik dan aspek buruk.

Azra menyatakan, manusia dalam pandangan Islam adalah makhluk rasional dan sekaligus mempunyai hawa nafsu kebinatangan, sehingga manusia bisa menjadi pribadi yang dekat dengan Tuhan, tetapi jika manusia tidak mampu mengendalikan nafsu kebinatangannya bisa menjadi makhluk yang paling hina. ${ }^{9}$ Oleh karena itu, perlu adanya pembatasan terhadap kebebasan agar manusia terhindar dari perbuatan jahat. Sedangkan secara psikologis, manusia pada dasarnya merupakan individu yang terdiri dari beberapa dimensi dan unsur penyusun dalam dirinya.

Adanya pembatasan dalam kebebasan bertujuan untuk membentuk kebiasaan baik pada santri, karena dengan adanya pembiasaan, diharapkan dapat membentuk aspek baik dalam diri manusia. Pembiasaan dalam pendidikan humanistik Islami merupakan pendidikan dengan tetap memperhatikan aspek kodrati manusia, baik ditinjau dari aspek agama, psikologis dan sosiologis. Sesuai dengan pernyataan Imarah, dalam pandangan Islam, kebebasan manusia merupakan hal yang sangat penting, karena hanya dengan kebebasan, manusia dapat mempunyai arti dalam hidupnya. ${ }^{10}$

Kebebasan dalam agama Islam, menurut Madani, ibarat kekang yang diberikan pada kuda yang sedang berlari, tidak ada ayat dalam al-Qur'an yang benar-benar menyatakan tentang kebebasan pada manusia, kecuali ayat yang berhubungan dengan kebebasan pada perbudakan. Ini berarti, dalam agama Islam kebebasan selalu dikaitkan dengan keadilan. ${ }^{11}$ Keadilan dalam Islam tidak berarti melakukan persamaan, adil berarti menempatkan sesuatu sesuai

9 Azyumardi Azra. Pendidikan Islam : Tradisi dan Modernisasi Menuju Milenium Baru (Ciputat : PT. Logos Wacana Ilmu,1999), h. 7.

10 Muhammad 'Imarah. Al-Islām wa Huqūq al-Insān (Beirut: 'Alim al- Ma'rifah, 1990), h. 13.

11 Abdul Hai Madani, "Freedom and Its Concept in Islam." International Conference on Humanities, Historical and Social Sciences 17,2 (Singapore, 2011), h. 116-117. 
pada tempatnya. Seperti dinyatakan oleh Begum dan Aman, keadilan menurut Hazrat Ali, merupakan suatu hal yang cerdas dan mulia, karena keadilan menempatkan sesuatu sesuai dengan tempatnya. ${ }^{12}$

Sesuai dengan pernyataan al-Atas, pendidikan adalah proses menanamkan sesuatu ke dalam diri sesorang, dengan tujuan akhir menjadi manusia sempurna (insān kāmil). Insān kāmil, bisa diartikan sebagai manusia yang mengabdikan diri hanya beribadah kepada Allah. ${ }^{13} \mathrm{Hal}$ ini sesuai dengan tujuan Allah menciptakan makhlukNya. ${ }^{14}$

Muțțahāri (1920-1979) mendefinisikan insān kāmil sebagai insan yang memiliki keseimbangan seluruh nilai-nilai insaninya. ${ }^{15}$ Hal ini berarti, insān kāmil bukanlah manusia taat, saleh, bijaksana dan penuh kasih. Insān kāmil adalah manusia yang semua nilainilai kemanusiaannya tumbuh dan berkembang secara harmoni dan seimbang. ${ }^{16}$

Hal ini mengindikasikan bahwa tujuan akhir pendidikan dalam Islam menyangkut seluruh aspek hidup manusia, baik berupa hubungan antara manusia dengan sang Khāliq (Allah SWT) maupun hubungan manusia dengan sesamanya. Untuk mencapai hal tersebut maka pendidikan humanistik islami perlu diterapkan dalam proses belajar mengajar.

Implikasi pendidikan humanistik Islami dapat dilihat pada model pembelajaran aplikatif pondok pesantren, model pembelajaran ini merupakan model pembelajaran dengan mengaplikasikan ilmu yang dimilikinya dan selama mempraktekkan keilmuan tersebut peserta didik tetap memperhatikan nilai-nilai yang ada pada agama Islam.

12 ShaguftaBegum and AneeqaBatoolAwan. “ Plato's Concept of Justice and Current Political Scenarioin Pakistan ."International Journal of Humanities and Social Science3, 11 (June, 2013), h. 82.

13 Syed Muhammad Naquib Al-Atas. "Understanding the Concept of Education in Islam." Harakah Daily (9 March, 2014).

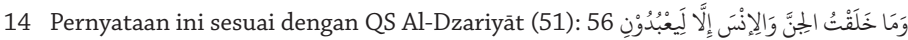
Artinya: Dan aku tidak menciptakan jin dan manusia melainkan supaya mereka mengabdi kepada-Ku.

15 Murțādā Muțțahārī. Insān-e Kāmil. (Isfāhān: Markaze Tahqīqāt Rayāne-i, t.t), 12 www. Ghaemiyeh.com(diakses pada tanggal 3 mei 2014). Lihat jugaMurțādā Muțțahārī.Yād-e Dāshtāhā-e Ustād Mutțāhārī, Jild Aval, Harf Alef.Tehrān va Qum : Sadrā, 1978), h. 282 - 307.

16 Murțādā Mutțahārī. "Insān-e Kāmil”. Ruznāmeh Risālat, 6135 (2/12/86), h. 17. 
Pembelajaran aplikatif pondok pesantren dapat dilakukan dengan cara memahami karakteristik santri dan cakupan materi, kemudian menyesuikannya dengan model/metode pembelajaran yang sesuai dan selama proses pembelajaran santri tidak diperbolehkan melanggar aturan-aturan agama Islam, sehingga pembelajaran aplikatif pesantren merupakan aplikasi dari pembelajaran humanistik Islami.

Sebagai hasil belajar yang diperoleh adalah output dan outcome. Output merupakan hasil belajar yang diperoleh langsung setelah proses pembelajaran, contohnya prestasi belajar, sedangkan outcome merupakan hasil pembelajaran dalam waktu yang lebih panjang, seperti kemampuan untuk melanjutkan ke jenjang pendidikan lebih tinggi dan kesempatan kerja di masyarakat.

Hal ini bertentangan dengan pembelajaran humanis dalam perspektif barat, yang mengaplikasikan pendidikan humanis sebagai kebebasan siswa tanpa batas, atau pendidikan humanis dalam perspektif Marxisme, yang mengartikan pendidikan humanis sebagai kebebasan yang dimiliki manusia adalah mutlak bahkan adanya agama dan aturan tuhan dianggap sebagai pengekang kebebasan manusia. Salah satu tokoh pendukung teori humanis non Islami adalah teori humanis yang dikemukakan oleh Tropiano.

Teori pendidikan humanis menurut Tropiano merupakan teori pendukung dari Paulo Freire yang menyatakan pendidikan adalah pembebasan, sehingga santri diberi kebebasan dalam menentukan proses belajar mengajar tanpa adanya tindakan guru yang manipulatif, baik berupa intimidasi, penolakan maupun sanksi. ${ }^{17}$

Teori ini berbeda dengan pendidikan humanistik Islami, karena dalam pendidikan humanistik Islami, pembebasan hanya dilakukan selama tidak bertentengan dengan ajaran Islam dan aspek kodrati manusia, sehingga pendidikan humanistik Islami tidak memberikan kebebasan santri secara sepenuhnya.

17 Carmelo Tropiano, "Paulo Freire. Social Change and Teaching of Gothic Literatur," College Quarterly 11, 2 (Spring, 2008), h. 3. 


\section{B. PENDIDIKAN HUMANISTIK ISLAMI}

Pendidikan humanistik merupakan pendidikan yang fokus pada potensi manusia untuk menemukan kemampuan yang dimilikinya dan mengembangkan kemampuan tersebut. Dalam paradigma humanis, manusia di pandang sebagai makhluk Tuhan yang memiliki fitrah-fitrah tertentu yang harus dikembangkan secara optimal dan fitrah manusia ini hanya bisa dikembangkan melalui pendidikan yang benar-benar memanusiakan manusia.

Gagasan tentang pendidikan humanis mengambil faham dari filsafat humanisme, yaitu faham filsafat yang menyatakan bahwa seorang manusia harus dihormati sebagai manusia seutuhnya. Para tokoh humanis ini berpandangan bahwa manusia berbeda dengan hewan, manusia mempunyai jiwa dan potensi yang layak untuk dikembangkan. ${ }^{18}$

\section{PENDIDIKAN HUMANISTIK DAN FAHAM- FAHAM HUMANISME DALAM PENDIDIKAN}

\section{Pendidikan Humanistik}

Teori pendidikan humanis pertama kali dikemukakan oleh Carl Roger (1902-1987), ${ }^{19}$ selain itu teori pendidikan humanis juga dikemukakan oleh Paulo Freire (1921-1997). Menurut Freire, pendidikan adalah pembebasan. Freire tidak setuju dengan model pembelajaran yang pada umumnya dilakukan di sekolah yang kemudian oleh Freire model pembelajaran tersebut disebut dengan Model pembelajaran bank. ${ }^{20}$

18 Haryu, "Aplikasi Pendidikan Humanistik dalam Dunia Pendidikan di Indonesia" Tadris 1,1 (2006), h. 79.

19 Carl Rogers (1902 - 1987) adalah tokoh psikologi humanistik yang ide-idenya terdapat baik dalam domain konseling, pendidikan, keperawatan atau politik. Menurutnya, agar tercipta masyarakat yang lebih baik, maka hubungan antar sesama manusia dalam bentuk empati dan secara aktif yang satu mau mendengarkan yang lain dan agar pendidikan menjadi upaya yang tidak siasia, santri perlu mempelajari materi yang memiliki makna pribadi bagi santri, karena pembelajaran tidak hanya melibatkan pikiran saja, tetapi juga melibatkan perasaan dan makna pribadi. Lihat Carl Rogers and H. Jerome Freiberg. Freedom to Learn Third Edition (New Jersey: Prentice Hall, Inc., 1994). amazon.com (diakses pada tanggal 31 Juli, 2016), h. 3-4.

20 Pada Model pembelajaran bank ada aktivitas yang membuat santri menjadi takut, yaitu berupa: penolakan, intimidasi dan sanksi. Lihat Carmelo Tropiano, "Paulo Freire, Social Change and Teaching of Gothic Literature," College Quarterly 11, 2 (Spring, 2008), h. 8. 
Model pembelajaran bank mengkondisikan santri hanya menerima pengetahuan yang diberikan oleh guru, sehingga guru berfungsi sebagai penabung dan santri sebagai penerima tabungan. ${ }^{21}$ Pembelajaran model bank, menyebabkan santri menjadi pasif, karena santri dipaksa untuk mengikuti pembelajaran yang diberikan guru. Pada saat pembelajaran dengan model bank hanya guru yang aktif, sementara santri hanya sebagai penerima pengetahuan yang diberikan guru.

Dengan demikian, dalam pendidikan dengan model bank atau banking concept education, guru sebagai penentu jalannya aktivitas pembelajaran, santri hanya menurut ketentuan yang telah ditetapkan dan setiap pelanggaran terhadap ketentuan yang telah ditetapkan akan dikenakan sanksi.

Paulo Freire (1921-1997) juga menyatakan bahwa pendidikan adalah proses pembebasan tanpa adanya tindakan guru yang manipulatif, baik berupa intimidasi, penolakan maupun sanksi. Teori ini sesuai dengan pedagogi konstruktivisme ${ }^{22}$ dan bertentangan dengan pedagogi behaviorisme yang dinyatakan oleh John B. Watson (18791958). ${ }^{23}$

\section{a. Implikasi Pendidikan Humanistik}

Implikasi dari pendidikan humanistik menurut Karthiyenen adalah: pendidikan harus berpusat pada anak, guru harus memperhatikan adanya perbedaan diantara individu, guru harus memahami anak, metode mengajar

21 Paulo Freire. Pedagogy of the Oppressed: 30 th Anniversary Edition, translated by Myra Bergman Ramos (New York: The Continuum International Publishing Group, 2005), h. 71.

22 Pendekatan konstruktivisme dikembangkan pada tahun 1980 dan 1990, bahkan lebih dahulu juga pernah dikembangkan teori ini oleh Bartlett (1932), yaitu teori tentang bagaimana seseorang mengingat kejadian dan Piaget (1971), yaitu teori tentang bagaimana anak belajar. Teori ini juga dikemukakan oleh Ausubel (1968), yaitu teori tentang bagaimana santri mengasimiliasikan apa yang dipelajari dengan apa yang sudah diketahui. Lihat William M. Reynolds Gloria E. Miller. Educational Psychology. Handbook of Psychology, Vol. 7 ( New Jersey : John Wiley \& Sons, Inc., 2003), h. -56 .

23 Behaviorime adalah teori pembelajaran yang dikemukakan oleh John B. Watson (1879-1958). Menurut Watson tidak ada kebutuhan untuk membuat asosiasi mental yang tidak teramati dalam menjelaskan perilaku manusia dan hewan. Tokoh behaviorist antara lain adalah JB Watson(1879 - 1958), FB Skiner (1904) dengan Operant Conditioning, Ivan Pavlop (1882) dan Thorndike (1874-1949). Lihat W. David Pierce and Carl D. Cheney. Behavior Analysis and Learning. Third Edition (New Jersey: Lawrence Erlbaum Associates Publisher, 2004), h. 13-14. 
yang digunakan harus disesuaikan dengan kebutuhan, minat, kemampuan dan sikap santri, guru tidak harus memaksa santri untuk disiplin dan guru bertindak sebagai teman. $^{24}$

Selanjutnya Specia dan Osman menyatakan, pendidikan sebagai praktik kebebasan adalah cara mengajar yang siapapun bisa belajar. Guru mengajar dengan cara pemberdayaan santri, tidak mengancam dan tidak diskriminatif. Mengajar merupakan tindakan yang menawarkan ruang untuk perubahan, dan menjaga lingkungannya dari pengaruh pengganggu. ${ }^{25}$

Pada dasarnya pendidikan humanistik adalah pendidikan yang mengutamakan hak-hak asasi manusia. Aslan dan Kepenecki menyatakan, pendidikan hak asasi manusia dapat didefinisikan sebagai pendidikan yang ditawarkan dalam rangka untuk menggugah kesadaran untuk kognisi, perlindungan, pemanfaatan dan peningkatan hak asasi manusia oleh santri dalam suasana pendidikan formal. ${ }^{26}$

b. Prinsip Pembelajaran Humanistik

Prinsip-prinsip pembelajaran humanistik seperti dinyatakan oleh Knight mencakup keterpusatan pada anak, peran guru yang tidak otoritatif, pemfokusan pada subjek didik yang terlibat aktif, dan sisi-sisi pendidikan yang kooperatif dan demokratif. ${ }^{27}$

Pendekatan yang digunakan dalam pendidikan humanistik menurut Nata adalah pendekatan individualistis, yaitu pendekatan yang menyatakan bahwa

24 P. Karthiyenan. "Humanistic Approaches of Teaching and Learning." Indian Journal of Research Paripex 2,7 (July, 2013), h. 58.

25 Akello Speciaand Ahmed A. Osman. "Ducationasa Practiceof Freedom: Reflection sonbell hooks." Journal of Education and Practice 6, 17 (2015), h. 195-196.

26 Canan Aslan and Yasemin Karaman-Kepenecki. "Human Rights Education: A Comparison of Mother Tongue Text Books in Turkey and France." Mediteranian Journal of Education Studies 13 (1) (2008), h. 101-102.

27 George R. Knight, Filsafat Pendidikan; Isu-isu Kontemporer dan Solusi Alternatif, Terj. Mahmud Arif. (Yogyakarta : Idea- Press, 2004), h. 110-111. 
setiap manusia memiliki bakat dan kecenderungan. Oleh karena itu, mereka harus diberi kebebasan sebebasbebasnya tanpa ada tekanan dan paksaan dari luar. ${ }^{28}$

Pendekatan humanistik merupakan pendekatan dengan teori pembelajaran konstruktivisme, yaitu proses pembelajaran dengan memberikan kesempatan kepada santri untuk membangun materi yang telah dipelajari dengan pengalaman yang dimilikinya.

Slavin mendefinisikan teori konstruktivisme sebagai teori dimana peserta didik secara individual menemukan dan mentransformasikan informasi yang kompleks, memeriksakan informasi yang baru terhadap aturan yang lama dan merevisinya jika aturan tersebut sudah tidak lagi bekerja. ${ }^{29}$ Dengan demikian, dalam pembelajaran ini santri tidak hanya sebagai penerima pengetahuan, tetapi juga diberikan kebebasan untuk mengembangkan kemampuan yang dimilikinya.

Dalam pembelajaran konstruktivisme menurut Henson, santri harus membangun pemahanam yang diperoleh melalui pembelajaran ke dalam pengalamannya sendiri. ${ }^{30}$ Weegar and Pacis menyatakan bahwa menurut teori belajar konstruktivisme, anak-anak dapat mengembangkan pengetahuan melalui partisipasi aktif dalam pembelajaran. ${ }^{31} \mathrm{Hal}$ ini membuat santri menjadi aktif dalam proses belajar mengajar tersebut.

Pendekatan prilaku belajar konstruktivisme menurut Psunder, pemberian sanksi sebagian besar dihindari karena konsekuensinya hampir tidak dapat diprediksi. Santri aktif dalam proses belajar mengajar yang aktif, pembangunan pengetahuan berasal dari learning by doing. ${ }^{32}$

28 Abudin Nata, Perspektif Islam Tentang Strategi Pembelajaran(Jakarta: Kencana, 2009), h. 148.

29 Robert E. Slavin. Educational Psychology Theory and Practice (Baltimore, Maryland: John Hopkin Unversity,1994), h. 224.

30 Kenneth T. Henson, "Foundations for Learner Centered Education : A Knowledge Base”, h. 18.

31 Mary Anne Weegar and Dina Pacis, "A Comparison of Two Theories of Learning Behaviorism and Constructivism as Applied to Face-to-Face and Online Learning". E-Leader Manila (2012), h. 6.

32 Majda Pšunder, Branka Ribič Hederih. "The Comparison between The Behavioral and 
c. Metode Pengajaran Humanis

Pada pengajaran humanis, guru mengajar dengan model pembelajaran konstruktivisme. Larochelle dan lain-lain menyatakan, guru dalam pembelajaran pada teori konstruktivisme berhasil merubah kebiasaan santri dan santri merekonstruksikan beberapa alternatif keadaan. Guru mengajarkan kepada santri beberapa konteks, kemudian fikiran santri dan guru didistribusikan dalam tindakan dan santri diberi kebebasan dalam merekonstruksikan kembali. Dalam pembelajaran ini, hal yang terpenting bukan hanya pengetahuan, tetapi juga kemampuan santri menciptakan beberapa kemungkinan dari materi yang disampaikan guru. ${ }^{33}$

Metode pengajaran humanistik merupakan metode pengajaran dimana aspek afektif sama pentingnya dengan aspek kognitif dan psikomotik, selain itu dalam pembelajaran humanistik kondisi emosional santri juga diperhatikan, karena kondisi emosional santri dapat mempengaruhi proses pembelajaran. Seperti dinyatakan oleh Khatib, dalam pembelajaran humanistik aspek aspek afektif sama pentingnya dengan aspek kognitif demikian juga dengan aspek emosional santri. Ketika santri bersedih dan tertekan dapat mengakibatkan kegagalan santri dalam proses pembelajaran. ${ }^{34}$

Hal yang sama juga dinyatakan oleh Dignya, yaitu Teori mengajar Humanisme memiliki beberapa pandangan baru pada pendekatan pengajaran seperti aktualisasi diri, belajar yang signifikan, hubungan emosional antara guru dan santri dan pengajaran yang berpusat pada santri. ${ }^{35}$

Constructivist Learning and Teaching."Informatol 43, 1(2010), h. 35-36.

33 MarieLarochelle dan lain-lain. Constructivism and Education (New York: Cambridge Universiry Press, 1998), h. 60.

34 Muhammad Khatib. "Humanistic Education:Concerns,Implications and Applications." Journal of Language Teaching and Research, 4, 1 (January 2013), h. 50.

35 DU Djingna. "Application of HumanismTheory in theTeachingApproach." CS Canada 3,1 (2012), h. 36. 


\section{Faham Pendidikan Humanistik menurut Liberalisme dan Agama Islam.}

Faham humanistik memandang, pendidikan sebagai proses memanusiakan manusia. Pendidikan idealnya harus membantu peserta didik tumbuh dan berkembang menjadi pribadi-pribadi yang lebih manusiawi, berguna dan berpengaruh di dalam masyarakatnya, bertanggung jawab, bersifat proaktif dan kooperatif.

Melihat realitas tersebut, maka sudah selayaknyalah pendidikan dikembalikan pada hakikat sesungguhnya, yaitu proses memanusiakan manusia dan merubah paradigma pendidikan yang memandang peserta didik sebagai objek.

a. Pendidikan Humanistik Menurut Faham Liberal

Humanisme liberal menurut Deshmukh, lahir dari ide sekelompok filsafat dan politik yang menegaskan, kebebasan dan kemandirian merupakan subyek diri individu, sehingga dia mengasumsikan, pada dasarnya manusia adalah bebas dan semua yang dilakukan manusia didasarkan pada pengalamannya. ${ }^{36}$ Menurut Lynch, pada masyarakat Liberal, pendidikan merupakan komoditas pasar, sehingga sekolah dikelola murni sebagai bisnis. ${ }^{37}$

Menurut Guttman untuk mendapatkan pendidikan terbaik, maka teori pendidikan liberal dan konservatif harus diterapkan. ${ }^{38}$ Kebebasan menurut Nelson untuk menguji dan melakukan kritik merupakan bagian yang paling penting bagi budaya demokrasi, sehingga tujuan utama pendidikan adalah kebebasan akademik. ${ }^{39}$ Oleh karena itu, menurut Parker, sekolah sebaiknya menggunakan sistem demokrasi deliberatif dengan alasan, mempunyai missi yang jelas dan mempunyai

36 Ajay P. Deshmukh, "Mathew Arnold and 'Liberal Humanism", InternationalReffered Research Journal 3, 32 (2011), h. 32.

37 Kathleen Lynch, "Neoliberalism and Marketiration: The Implications for Higher Education", European Educational Research Journal5,2 (2006), h. 1. 10.

38 Ammy Gutman, Democratic Education (New Jersey: Princeton University Press, 1998), h.

39 Jack L. Nelson, “Academic Freedom, Institutional Integrity, and Teacher Education”, h. 66. 
kurikulum yang sesuai dengan tujuan pendidikan. ${ }^{40}$

Berdasarkan uraian tersebut dapat disimpulkan bahwa pendidikan humanistik menurut faham liberal, merupakan pendidikan dimana anak didik dijadikan komoditas pasar, sehingga pendidikan dikelola secara bisnis. Tujuan pendidikan dalam faham ini lebih kepada keuntungan semata dan manajemen yang digunakan juga manajemen perusahaan.

b. Pandangan Humanistik Menurut Agama Islam

Gerakan pendidikan humanistik menurut Dosset dikembangkan di Barat sebagai penolakan terhadap metode pembelajaran gereja yang kaku.

Gerakan humanis dalam Islam klasik dikembangkan dari keprihatinan filologis kehilangan bahasa dan melibatkan revitalisasi tata bahasa dan leksikografi. Gerakan ini akan berkembang dan ditandai oleh dua ciri yaitu kefasihan dalam pidato dan komposisi sastra yang meniru model klasik Arab. ${ }^{41}$

Humanisme dalam pandangan Islam menurut Jamalzadeh dan Tavasolli, menempatkan manusia sebagai makhluk ciptaan Allah yang memiliki jiwa ilahi dan memiliki sifat bersih. Manusia mempunyai tempat sebagai utusan tuhan (khalïfatullāh fì alard) dan bahkan malaikat bersujud di hadapannya. Manusia memiliki kebebasan untuk menentukan jalan hidupnya, manusia adalah makhluk yang mempunyai pengetahuan dan manusia adalah makhluk yang bertanggung jawab. ${ }^{42}$

Hal yang sama juga dinyatakan oleh Husein. Ada kekeliruan tentang humanisme, karena selama ini humanisme diartikan sebagai anti agama, padahal humanisme lahir karena agama, mereka keberatan dengan pencitraan Allah yang terkesan tidak peduli dengan penderitaan manusia. Menurut Islam manusia

40 Walter Parker, "Feel Free to Change Your Mind: A Respons to The Potential for Deliberative", Democratic and Education 19,2 (2011), h. 4.

41 Rena D. Dossett."The Historical Influence of Classical Islam on Western Humanistic Education." International Journal of Social Science and Humanity, 4, 2 (March,2014), h. 90-91.

42 Abdoreza Jamalzadeh and Seyedeh Sareh Tavasoli. "Human Verivy Humanism, Existesionalism and Islam, h. 391. 
adalah makhluk bebas, namun dia akan diminta pertanggung jawaban atas apa yang telah dilakukannya. ${ }^{43}$

Kaseem menyatakan, kebebasan dalam al-Qur'an berarti kesatuan antara objektif dan subyektif, sosial dan alami, individual dan plural dan pengajaran dalam Islam berarti keselarasan antara kekuatan-kekuatan fitrah yang pada akhirnya mengisi pada tingkat individual dan sosial. ${ }^{44}$

Menurut Taher, manusia adalah makhluk bebas dan berkehendak, namun dalam kehidupan beragama manusia tidak pernah terlepas dari etika dalam masyarakat. Ada tiga tahap untuk mendapatkan kehidupan beretika, yaitu melalui iman, melakukan pelayanan dan bersyukur kepada Allah SWT. ${ }^{45}$

Dengan demikian, humanisme dalam pandangan Islam, menghargai manusia sesuai fitrahnya sebagai makhluk yang memiliki kebebasan dalam menentukan jalan hidupnya, namun kebebasan manusia adalah kebebasan yang harus memberikan pertanggung jawaban atas perbuatannya di hadapan Allah.

\section{PEMBELAJARAN HUMANISTIK ISLAMI}

Humanistik Islami kadang ada yang menyebutnya sebagai humanistik religius dan merupakan pendidikan humanistik yang didasari pada agama Islam. Pembelajaran humanistik Islami merupakan pembelajaran yang memberikan kesempatan sebebasbebasnya kepada santri, namun tetap dalam batasan yang tidak melanggar ketentuan agama Islam.

Lembaga pendidikan yang menerapkan sistem pendidikan humanistik Islami biasanya adalah pondok pesantren. Hal ini disebabkan pesantren memiliki kemampuan untuk menciptakan dasar yang kuat dari pendidikan agama, seperti dinyatakan oleh

43 Mahmoud Husein. "The Muslim phase of humanism" The Unesco Courier (October-December, 2011), h. 22-24.

44 Kaseem, Abdul Satar. "The Concept of Freedom in the Qur'an", American International Journal Of Contemporary Research 2,2 (April, 2012), h. 165.

45 Ali Raza Tahir, " The Concepts of Ethical Life in Islam.: Interdisiplinary Journal of Contemporary Research in Business 3, 9 ( January, 2012 ), h. 1367-1368. 
Mukodi, Gaya pendidikan pondok pesantren bisa disebut sebagai humanisme religius, hal ini disebabkan oleh tiga faktor, yaitu: suasana lembaga, metode pengajaran yang didasarkan pada humanisme agama, dan pesantren dapat menjadi kesetimbangan pada masyarakat sekitarnya ${ }^{46}$

Dengan demikian, indikator pendidikan humanistik Islami dalam penelitian ini dilihat dari proses pembelajaran yang terdiri dari metode pembelajaran yang digunakan, peran guru, respon siswa dalam belajar, suasana lembaga yang kondusif dan peran guru sebagai fasilitator.

\section{E. METODE PEMBELAJARAN APLIKATIF PONDOK PESANTREN MERUPAKAN IMPLIKASI PEMBELAJARAN HUMANISTIK ISLAMI}

Pendidikan humanistik Islami mencakup dua konsep yang diintegrasikan, yaitu pendidikan humanis dan pendidikan Islam, hal ini berarti pendidikan humanistik Islami adalah pendidikan memanusiakan manusia selama tidak bertentangan dengan ajaran Islam.

Konsep pendidikan humanistik Islami berbeda dengan pendidikan humanistik versi Barat. Pendidikan humanis versi Barat menuntut adanya kebebasan supaya martabat santri terjamin dan kebebasan tidak terjadi manakala santri terisolasi oleh hal-hal di luar dirinya. Humanistik versi Barat tidak dibatasi oleh nilainilai apapun termasuk nilai dari ajaran agama. Dalam pendidikan humanistik Islami atau humanistik religious pendidikan diarahkan untuk menjadikan manusia dekat dengan Tuhan melalui pengalaman manuia. ${ }^{47}$

Implementasi pendidikan humanis dalam pembelajaran perspektif Islam merupakan cara guru memberikan kebebasan kepada santri dalam berpikir dan bertindak sesuai dengan prinsipprinsip keislaman dan kemanusiaan. Dalam metode belajar yang

46 Mukodi. Dosen STKIP PGRI Pacitan.

47 Musthofa. "Pendidikan Humanis dalam Islam." Kajian Islam 3, 2 (2 Agustus, 2011), h. 160. 
humanis, guru harus mengoptimalkan seluruh potensi santri agar dapat berpikir kritis dan mengembangkan kemampuannya dalam keterampilan dan sikap. ${ }^{48} \mathrm{Hal}$ ini dapat dilihat pada pembelajaran aplikatif Pondok Pesantren.

Model pembelajaran aplikatif merupakan model pembelajaran yang menyatakan bahwa, kemampuan seseorang dapat dibentuk melalui serangkaian latihan yang sungguh-sungguh secara berulang-ulang dan difokuskan pada kegunaan yang diharapkannya. Pada pelaksanaannya diharapkan suasana pembelajaran dibuat sedemikian rupa sehingga siswa merasa aman, nyaman, dan menyenangkan. Ini yang dapat membangkitkan semangat belajar siswa. Pembelajaran aplikatif pondok pesantren merupakan aplikasi dari pembelajaan humanistik Islami, karena pembelajaran ini memanusiakan manusia dengan tetap berada sesuai dengan nilai-nilai keislaman.

Salah satu contoh guru yang professional dan menerapkan pendidikan humanistik Islami adalah Nabi Muhammad SAW. Menurut Daniarto, dalam memberikan pembelajaran kepada muridnya Nabi Muhammad SAW menggunakan metode sebagai berikut: 1). Metode keteladanan, 2). Metode pentahapan dan pengulangan, 3). Metode Tanya jawab 4). metode diskusi, 5). Metode alat peraga dan eksperimen, 6). Metode situasional dan kondisional, dan 7). Metode membangkitkan perhatian dengan memberikan pujian dan sanksi, memberikan nasehat dan motivasi serta memberikan hadiah. ${ }^{49}$

Dari beberapa metode pembelajaran humanistik Islami tersebut dapat disimpulkan, bahwa metode pembelajaran humanistik dalam penelitian ini merupakan metode yang dapat mengakibatkan timbulnya pembiasaan pada anak, sehingga metode yang digunakan dalam proses pembelajaran humanistik Islami mendorong tumbuhnya pembiasaan dalam diri santri,

48 Sumarlin Adam. "Pendidikan Humanis dalam Perspektif Islam(Konsep dan Implementasinya dalam Proses Belajar Mengajar)." Tadbir3,1 (Februari, 2015), h. 128. Diakses melalui http://journal.iaingorontalo.ac.id/index.php/timpi pada tanggal 26 September 2016.

49 Marlin Daniarto. "Metode Pendidikan dan Pengajaran Nabi Muhammad SAW dalam Proses Belajar Mengajar."Al-Jabar (14 Mei, 2011). 
seperti metode keteladanan, metode pengulangan, metode diskusi, metode tanya jawab dan bahkan dalam proses pembelajaran humanistik Islami masih diterapkan adanya reward dan punishment dengan tujuan menumbuhkan sisi pembiasaan hal-hal baik dalam diri santri. Kesimpulan besar dari penelitian ini adalah "pendidikan merupakan proses pembiasaan."

a. Metode Pembelajaran di Pondok Pesantren

Kegiatan belajar mengajar juga merupakan bentuk penyelenggaraan pendidikan dengan memadukan kegiatan pendidikan yang berkesinambungan dan sistematis agar diperoleh hasil sesuai dengan yang diinginkan. Penyelenggaraan pendidikan di pondok pesantren ini secara garis besar terdiri dari pendidikan formal dan pendidikan non-formal..$^{50}$

Kegiatan pendidikan di pondok pesantren umumnya dilakukan sesuai dengan jadwal yang telah ditentukan, sehingga model pendidikan di tempat ini adalah model pedagogy behaviorisme yang merupakan bentuk kebalikan dari pedagogy konstruktivisme.

Menurut Ellias, dalam pembelajaran dengan behaviorisme adanya kontrol yang sangat kuat terhadap tujuan, materi, lingkungan dan pegukuran hasil belajar. Sehingga teori ini banyak dikritik dan dianggap sebagai pedagogi penindasan, karena proses pembelajaran ini merupakan model pembelajaran yang tidak menghargai kondisi anak, keinginan anak dan minat dari pembelajar. Pedagogi ini menurut para tokoh humanis secara psikologis menindas santri, karena menghambat kreativitas dan pengembangan potensi anak. ${ }^{51}$

\section{F. KUALITAS OUTCOME}

Outcome merupakan hasil jangka panjang: dampak jangka panjang terhadap individu, sosial, sikap, kinerja, semangat, sistem,

50 Observasi di PPST Ar-Risalah. Pada tanggal 9-10 Oktobe 2013.

51 John L. Ellias, Paulo Freire,Pedagogue of Liberation (Florida : Kriegar Publishing Company, 1994), h. 123. 
penghasilan, pengembangan karir, kesempatan pendidikan, kerja, pengembangan dari lulusan untuk berkembang, dan mutu pada umumnya.

Mukrima menyatakan, Outcome adalah hasil yang terjadi setelah kegiatan jangka pendek, output terlebih dahulu dikeluarkan oleh sekolah, baru dihasilkan outcome. ${ }^{52}$ Sedangkan Roger menyatakan, outcome adalah hasil pemberian pelayanan atau keuntungan yang diperoleh pengguna pelayanan. ${ }^{53}$

Definisi outcome belajar dinyatakan oleh Mahir sebagai hasil belajar yang dilihat tidak hanya sekali, tetapi sebagai sebuah proses berulang yang melibatkan guru dan santri. ${ }^{54}$

Lembaga pendidikan setelah mengalami proses pembelajaran menghasilkan keluaran pendidikan. Keluaran pendidikan ini bisa mengandung dua pengertian yaitu output dan outcome. Kedua keluaran tersebut mempunyai pengertian yang berbeda. Oleh karena itu maka perlu dilakukan menjelaskan tentang pengertian output dan outcome serta perbedaan keduanya.

Output didefinisikan sebagai hasil (produk) lansung yang diperoleh dari input, sedangkan outcome merupakan efek lanjutan dari output. ${ }^{55}$ Output sekolah merupakan bentuk dari prestasi sekolah yang dihasilkan dari proses/perilaku sekolah. Output sekolah dinyatakan tinggi, jika prestasi sekolah, dalam hal ini prestasi belajar siswa tinggi, baik dari segi prestasi akademik maupun non akademik.

Nilai akademik siswa dapat dilihat dari Nilai Ujian Semester, Nilai Ujian Nasional, Karya Ilmih dan lomba akademik. Sedangkan prestasi non akademik dapat dilihat dari IMTAQ, kejujuran, kesopanan, olahraga dan kegiatan ekstrakurikuler lainnya.

52 Syifa S. Mukrima. 53 Metode Mengajar dan Pembelajaran. (Universitas Pendidikan Indonesia : Bandung, 2014), h. 13.

53 Steve Rogers. Performance Management in Local Government (Jesica Kindley Publisher : London, 1990), h. 24.

54 Angela Mahir. "Learning Outcome in Higher Education: Implication For Curriculum Design and Student Learning." Journal of Hospitality, Leisure, Sport and Tourism 3, 2 (2004), h. 50/46-54.

55 Outputs, outcomes and impacts arising from the HRB's 2000-09 grants portfolio (February, 2014), h. 14/1-93. 
Anggraini mendefinisikan output sebagai hasil yang dicapai dari suatu program, aktivitas, dan kebijakan, sehingga output adalah keluaran yang bisa dikendalikan dari dalam institusi, contoh bentuk input dalam pendidikan adalah angka kelulusan siswa dalam menempuh Ujian Nasional (UN). ${ }^{56}$ Dengan demikian, informasi dari output dalam bidang pendidikan dapat dilihat dari prestasi akademik berupa nilai ujian Nasional (UN) yang dicapai siswa.

\section{G. KUALITAS OUTCOME SANTRI PONDOK PESANTREN DARUN NAJAH, JAKARTA.}

Outcome pendidikan merupakan dampak jangka panjang yang diperoleh individu dari proses pembelajaran yang diterimanya. Hal ini bisa dilihat dari kualitas lulusan, berupa kemampuan santri melanjutkan pendidikan pada jenjang yang lebih tinggi dan kemampuan santri melakukan peran aktif dalam masyarakat baik dalam hal memperoleh pekerjaan dan aktivitas bermanfaat lainnya.

1. Kemampuan melanjutkan pendidikan lebih tinggi.

Santri Darunnajah diterima di UGM, TTB, IPB dan IAIN Sunan Ampel atas beasiswa dari Departemen Agama. Bahkan banyak diantara mereka yang melanjutkan pendidikan ke luar negeri.

Negara-negara tempat santri alumni pondok pesantren Darun Najah melanjutan pendidikan mereka yaitu: Malaysia, Kairo (Mesir), Madinah dan Inggris, sedangkan dengan Pakistan baru pada tahun 2017 ini dibuka kerjasama.

2. Kemampuan alumni memperoleh pekerjaan

Pondok pesantren Darunnajah, Ulujami Jakarta merupakan salah satu lembaga pendidikan yang sudah lama berdiri dan di pondok pesantren santri dibiasakan hidup disiplin dalam menjalankan tugas dan kewajiban tepat waktu dan santri juga

56 Hanjar Giri Anggraini. "Analisis Output Dan Outcome Bidang Pendidikan Dalam Era Otonomi Daerah Di Jawa Tengah. "Jurnal Pendidikan Eknomi Dinamika Pendidikan IX, 1 (Juni 2014), h. $73 / 70-82$. 
dibiasakan dengan hidup mandiri. Hal ini dimaksudkan agar pondok pesantren mempunyai outcome (keluaran).

Outcome dalam jangka panjang antara lain ditunjukkan dengan kemampuan alumni memperoleh kesempatan kerja. Outcome juga mencerminkan berfungsinya keluaran dari kegiatan-kegiatan dalam suatu program. Kualitas outcome yang baik ditunjukkan dengan beragamnya ranah pekerjaan yang dapat diperoleh oleh para alumni.

Santri tamatan dari Pondok Pesantren Darunnajah memperoleh pekerjaan tidak hanya sebagai ustadz/ustadzah, tetapi juga banyak dari para lulusan bekerja pada bidang/ profesi lain. Saat ini lulusan (alumni) dari pondok pesantren Darunnajah menempati posisi sebagai professional pada bidang yang cukup variatif, baik yang menjadi pegawai pemerintah maupun bekerja di perusahaan swasta.

Alumni pondok pesantren Darunnajah saat ini sudah ada yang menjadi wakil menteri hukum dan hak asasi manusia, anggota DPRD provinsi kepulauan Riau, wakil dekan, dosen, direktur dalam bidang pendidikan dan bahkan kepala desa Cidokom dan pengusaha. Hal ini mengindikasikan bahwa alumni pondok pesantren Darunnajah mempunyai kualitas outcome yang baik, sehinga tidak ada lagi anggapan bahwa alumni pesanten mempunyai masa depan suram karena sulitnya mendapatkan pekerjaan.

Pijakan utama pondok pesantren Darunnajah sebagai pesantren modern (khalaf) adalah menjaga paradigma budaya lama yang baik dan mengambil budaya baru yang berkualitas. Hal inilah yang menjadi penyebab saat ini kualitas outcome menjadi baik. Hal ini juga didukung oleh model pembelajaran pondok pesantren yang aplikatif. Keadaan ini membuat santri cukup terampil dan terbiasa ketika menghadapi dunia kerja.

Pondok pesantren Darunnajah memahami tujuan pendidikan Islam berbasis modern, yaitu: 1). memiliki akhlak dan moralitas yang tinggi, 2). menggapai kebahagiaan dunia dan akhirat, 
dimana kebahagiaan dunia biasa digapai melalui prestasi, profesi, keterampilan dan sains, serta 3). menjalin hubungan sosial kemasyarakatan untuk membangun solidaritas muslim di seluruh dunia.

Alumni dari Pondok Pesantren Darunnajah bersikap professional, agamis dan hambel. Hal inilah yang membuat alumni pondok pesantren Darunnajah dapat diterima kehadirannya baik di kalangan masyarakat maupun dunia kerja.

\section{H. KESIMPULAN}

Pondok pesantren Darunnajah merupakan salah satu bentuk pesantren modern (khalaf), sehingga pembelajaran di pondok pesantren ini dilakukan dalam bentuk klasikal (kelas). Pondok Pesantren Darunnajah tidak memberikan pembelajaran kitab kuning, sehingga tidak mengenal adanya metode, bandongan, wetonan, dan sorogan.

Untuk meningkatkan kualitas outcome pendidikan dapat dilakukan melalui pembiasaan yang diimplikasikan dalam model pembelajaran aplikatif. Pembelajran aplikatif dilakukan hampir di semua mata pelajaran, terutama mata pelajaran bahasa Arab maupun bahasa Inggis.

Kualitas outcome pondok pesantren Darunnajah yang baik, dilihat melalui kualitas alumninya yang banyak diterima baik di beberapa bidang pekerjaan (profesi) maupun di kalangan masyarakat. 


\section{DAFTAR PUSTAKA}

Adam, Sumarlin. "Pendidikan Humanis dalam Perspektif Islam

(Konsep dan Implementasinya dalam Proses Belajar Mengajar)." Tadbir 3,1 (Februari, 2015) : 128. Diakses melalui http://journal.iaingorontalo.ac.id/ index.php/ tjmpi pada tanggal 26 September 2016.

Al-Hazami, Khalid Abdul.Ușūl al-Tarbiyah al-Islāmīyah, al-Madīnah al- Munawwarah: Dār 'Alam al-Kutub, 2000.

Ali, Shariati. Jihad and Shahadat. Iranian Chamber Society, April 10, 2014.

Azra, Azyumardi. Pendidikan Islam: Tradisi dan Modernisasi Menuju Milenium Baru, Ciputat: PT. Logos Wacana Ilmu,1999.

Anggraini, Hanjar Giri. "Analisis Output dan Outcome Bidang Pendidikan Dalam Era Otonomi Daerah Di Jawa Tengah." Jurnal Pendidikan Eknomi Dinamika Pendidikan IX, 1, Juni 2014.

Asman, Canan Aslan and Karaman-Kepenecki Yasemin. "Human Rights Education: A Comparison of Mother Tongue Text Books in Turkey and France." Mediteranian Journal of Education Studies 13 (1), 2008.

Begum, Shagufta Begum and Aneeqa Batool Awan "Plato's Conceptof Justiceand Current Political Scenarioin Pakistan." International Journal of Humanities and Social Sciences,11 June, 2013.

Binti Fatah Yasin, Raudatul Firdaus and Jani, Mohammad Shah. "Islamic Education: The Phylosophy, Aim, and Main Feature." International Journal of Education and Research 1, 10 Oktober, 2010.

Daniarto, Marlin Daniarto. "Metode Pendidikan dan Pengajaran Nabi Muhammad SAW dalam Proses Belajar Mengajar." Al-Jabar 14 Mei, 2011. 
Deshmukh, Ajay P. "Mathew Arnold and 'Liberal Humanism", International Reffered Research Journal 3, 32, 2011.

Djingna, DU. "Application of Humanism Theory in the Teaching Approach." CS Canada 3, 1, 2012.

Dossett, Rena D."The Historical Influence of Classical Islam on Western Humanistik Education." International Journal of Social Science and Humanity, 4, 2 March, 2014.

E. Miller, William M. Reynolds Gloria. Educational Psychology. Handbook of Psychology, Vol. 7, New Jersey : John Wiley \& Sons, Inc., 2003.

Ellias, John L.Paulo Freire,Pedagogue of Liberation, Florida: Kriegar Publishing Company, 1994.

Freire, Paulo. Pedagogy of the Oppressed: $30^{\text {th }}$ Anniversary Edition, translated by Myra Bergman Ramos, New York: The Continuum International Publishing Group, 2005.

Gutman, Ammy. Democratic Education, New Jersey: Princeton University Press, 1998.

Haryu, "Aplikasi Pendidikan Humanistik dalam Dunia Pendidikan di Indonesia" Tadris 1,1, 2006.

Hamm, Ibrahim Mohammad, "Islamic Perspective of Education and Teachers”, European Journal of Social Science 30, 2, 2012.

Henson, Kenneth T. "Foundations for Learner Centered Education: A Knowledge Base".

Husein, Mahmoud. "The Muslim phase of humanism" The Unesco Courier, October - December, 2011.

Karthiyenan, P. "Humanistik Approaches of Teaching and Learning." Indian Journal of Research Paripex 2, 7, July, 2013.

Kaseem, Abdul Satar. "The Concept of Freedom in the Qur'an", American International Journal Of Contemporary Research 2, 2, April, 2012.

Khatib, Muhammad."HumanistikEducation:Concerns, Implications 
and Applications." Journal of Language Teaching and Research, 4, 1, January 2013.

Knight, George R. Knight, Filsafat Pendidikan; Isu-isu Kontemporer dan Solusi Alternatif, Terj. Mahmud Arif. (Yogyakarta : Idea- Press, 2004).

Larochelle, Marie dan lain-lain. Constructivism and Education, New York: Cambridge Universiry Press, 1998.

Lynch, Kathleen, "Neoliberalism and Marketiration : The Implications for Higher Education", European Educational Research Journal 5, 2, 2006.

Madani, Abdul Hai Madani, "Freedom and Its Concept in Islam." International Conference on Humanities, Historical and Social Sciences 17, 2, Singapore, 2011.

Mahir, Angela. "Learning Outcome in Higher Education: Implication For Curriculum Design and Student Learning." Journal of Hospitality, Leisure, Sport and Tourism 3, 2, 2004.

Majda Pšunder, Branka Ribič Hederih. "The Comparison between The Behavioral and Constructivist Learning and Teaching."Informatol 43, 1, 2010.

Muhammad 'Imarah. Al-Islām wa Huqūq al-Insān, Beirut: 'Alim alMa'rifah, 1990).

Mukrima, Syifa S. Mukrima. 53 Metode Mengajar dan Pembelajaran. Universitas Pendidikan Indonesia : Bandung, 2014.

Muțṭahāri, Murțāda >. Insān-e Kāmil, Isfāhān: Markaze Tahqīqāt Rayāne-i, t.t. www.Ghaemiyeh.com,diakses pada tanggal 3 mei 2014. Lihat juga Murțādā Muțțahārī.Yād-e Dāshtāhāee Ustād Muțtāhārī, Jild Aval, Harf Alef.Tehrān va Qum : Sadrā, 1978), 282 - 307.

Musthofa. "Pendidikan Humanis dalam Islam." Jurnal Kajian Islam 3, 2, Agustus, 2011.

Nata, Abudin.Perspektif Islam Tentang Strategi Pembelajaran, Jakarta: Kencana, 2009. 
Naquib Al-Atas, Syed Muhammad "Understanding the Concept of Education in Islam.” Harakah Daily, 9 March, 2014.

Parker, Walter. "Feel Free to Change Your Mind : A Respons to The Potential for Deliberative", Democratic and Education 19, 2, 2011.

Pierce, W. David and Cheney, Carl D. Behavior Analysis and Learning. Third Edition, New Jersey: Lawrence Erlbaum Associates Publisher, 2004.

Rayan, Sobhi. "Islamic Philosophy of Education."International Journal of Humanities and Social Science 2,19, Special Issue, October, 2012.

Rogers, Carl and Freiberg, H. Jerome. Freedom to Learn Third Edition, New Jersey: Prentice Hall, Inc., 1994. amazon. com, diakses pada tanggal 31 Juli, 2016.

Rogers, Steve. Performance Management in Local Government, Jesica Kindley Publisher: London, 1990.

Slavin, Robert E. Educational Psychology Theory and Practice, Baltimore, Maryland: John Hopkin Unversity,1994.

Specia, AkelloandOsman, Ahmed A."Ducationasa Practice of Freedom: ."Journal of Education and Practice 6, 17, 2015.

Tahir, Ali Raza Tahir , “The Concepts of Ethical Life in Islam.: Interdisiplinary Journal of Contemporary Research in Business 3, 9, January, 2012. Carmelo. "Paulo Freire, Social Change and Teaching of Gothic Literature," College Quarterly 11, 2, Spring, 2008.

UNICEF. “Defining Quality in Education."United Nations Children's Fund, June, 2000.

Weegar, Mary Anne and Pacis, Dina. "A Comparison of Two Theories of Learning Behaviorism and Constructivism as Applied to Face-to-Face and Online Learning”. E-Leader Manila, 2012. 